\title{
Gendered risks and opportunities? Exploring teen girls' digitized sexual identities in postfeminist media contexts
}

\begin{abstract}
In debates on young people's engagements with new media, social networking sites (SNSs) have been explored as potentially democratizing spaces allowing a wider spectrum of young users to engage with digital technology than ever before. In relation to gender difference, SNSs are viewed as places that have opened up girls' and women's use of new media, building on earlier claims about how online practices like personal websites and blogging have revolutionized girls' access to and uses of digital technology. On the other hand, there are prominent public debates over children and sexualization, for example, that position young people and particularly girls as at risk of exposure to online content or SNSs that are not age appropriate, and which may contain adult sexually explicit content or pornography, or even put young people at risk from online paedophiles. In this article we try to think through and beyond SNSs as sites of both gendered risk and opportunity, drawing on qualitative data from a
\end{abstract}

\section{KEYWORDS}

risk

postfeminism sexualization pornification porno-chic social networking sites cyberbullying 
UK study of teens' uses of the SNS Bebo. We discuss and trouble what gendered and sexualized risk and opportunity might mean in relation to user-generated content and peer-to-peer networks. We situate peer networks as operating within wider postfeminist, pornified media contexts which may intensify dynamics like sexual objectification of girls' bodies. But we also illustrate how girls navigate such trends in complex ways exploring instancos of nomn-chis porformonce and corunlizod cy horbullying.

\section{INTRODUCTION: RETHINKING RISK AND GENDER}

In this article we start by scrutinizing the categories of online risk and opportunity that have organized recent discussions about gender and young people's online engagements, particularly with social networking sites (SNSs) (see Livingstone 2008; Livingstone and Brake 2010; Livingstone and Helsper 2009). Livingstone and Haddon's recent comprehensive European Union wide research report EU Kids Online (2009) reviewed a range of literature on young people and new media that suggested there are 'significant gender differences' in online risk and opportunity, with boys apparently 'more likely to encounter (or create) conduct risks and girls more affected by content and contact risks' (Livingstone and Haddon 2009: 16). The report suggests that while 'both boys and girls are at risk of online bullying', 'boys appear more likely to seek out offensive or violent content, to access pornographic content or be sent links to pornographic websites, to meet somebody offline that they have met online and to give out personal information'; girls appear to be 'more likely to be upset by offensive, violent and pornographic material, to chat online with strangers, to receive unwanted sexual comments and to be asked for personal information, though they are wary of providing it to strangers' (Livingstone and Haddon 2009: 16). In its recommendations, the EU Kids Online report also suggests, however, that we have little qualitative understandings of user-generated content created in SNSs, but 'strong [gender] differences in patterns of use therefore patterns of risks persist', so we need 'awareness-raising and strategies to encourage coping and resilience should address girls and boys differently' (Livingstone and Haddon 2009: 23).

As a first response to thinking about the framing of Internet engagement within a binary of risk and opportunity, sociological theorists have put the discourse of risk under scrutiny suggesting we need to be careful of how models of capitalist consumption have created a 'risk society' and audit culture of accounting for the self/others (Beck 1992). Risk as a category is deconstructed in Foucault-inspired governmentality literature that points out how risk categories are created in binary opposition to healthy and enterprising selves, where risk becomes a central dimension of regulation and management (Rose 2001, quoted in Sears 2011). Scholars also suggest in contemporary contexts dominated by neo-liberal models of ideal reflexive, rational and freely choosing selves individuals are charged with minimizing risk - that which they undertake or are exposed to - incited to actively practice risk aversion (Lupton 1999, quoted in Sears 2011).

Educationally speaking, risk aversion implies a conscious rational actor who should be trained up into risk aversion as part of making safe choices in a dangerous world, a discourse which overlays much educational policy (Ball 2008). Opportunity, in contrast, appears to be set in opposition to risk, as its positive, healthy, safe, exploratory counterpoint. We argue that we need to trouble 
the risk framework and exceed the risk/opportunity binary, since, as we will illustrate, activities can be both risky and opportunistic at the same time (Livingstone 2008). In short, we want to draw attention to the need for caution in interpreting activities and identities solely through the reductive lens of measuring risky behaviour found in neo-liberal, audit cultures. Our analysis will illustrate that gender relations are more messy and complex than rational agents doing risk aversion vis-à-vis risky or healthy options.

We draw upon feminist commentators in media studies who are suggesting that girls and young women may be participating more than ever in new media technologies, but must also cope with reinvigorated conditions of sexual objectification that characterize postfeminist, neo-liberal media contexts (Gill 2008,2011 ). Postfeminism can be understood as a discourse where feminist recognition of sexism is vehemently rejected or viewed as obsolete (McRobbie 2008) leaving a space for intensified stereotypes of femininity and masculinity to thrive. In the next section we briefly explore the thesis that the wider popular cultural context is 'postfeminist', that is, rather than challenging gender norms (as with feminism) popular culture is now actually fetishizing and celebrating idealized, binary versions of extreme gender norms, hyper-sexualized femininity for girls and hard, predatory masculinity for boys (Renold and Ringrose, in press).

Going beyond a media, cultural or textual analysis, however, we respond to the need for qualitative data on young people's uses of SNSs, with research findings that illustrate how girls engage with and negotiate postfeminist discourses in complex ways. Drawing on a post-structural and psychosocial research tradition (e.g. Walkerdine, Lucey and Melody 2001) we explore how girls are 'doing' gendered and sexualized performances of self, re-theorizing the complexities of gendered risk and opportunity in both online and offline spaces. For instance, the research data explored in this article indicate that girls not only are 'upset' by pornographic material (Livingstone and Haddon 2009) but also use, revise, and therefore negotiate, porno-discourses in complex ways in their digitized identity construction, which may afford new creative opportunities for sexual subjectivity online, in line with shifting discursive formations of femininity. We also suggest the need to complicate and widen the binary of adult predator and vulnerable child in conventional media risk frameworks (Byron 2008) to include an understanding of gendered and sexualized peer-to-peer, user-generated content and relationships in SNSs.

\section{POSTFEMINIST 'SEXUALIZED’ AND ‘PORNIFIED’ MEDIA CONTEXTS?}

Writing in the UK context, Angela McRobbie (2008) describes postfeminism as a set of defensive gender discourses and politics in our contemporary era, that position feminism as having achieved its aims and as therefore now not only obsolete but regressive and backwards. In light of this backlash, McRobbie suggests that we are witnessing a new sexual contract for girls in many western contexts, whom having been allowed entry into civic society must now perform a 'postfeminist masquerade' where they are subject to more intensified technologies of bodily perfection and visual display as 'feminine subjects' in a current 'fashion and beauty' system that privileges oppressive forms of idealized white femininity (2008: 71). This performance entails hyper-sexualized displays of sexy femininity, what McRobbie has also called a predominance of porno-chic aesthetic to compensate for the implication that girls may become 
too much like boys or men, given girls' increased presence in and over 'success' in education and paid work (Ringrose 2007: 471).

Rosalind Gill (e.g. 2007, 2008: 40) has theorized some key elements of the postfeminist media context and 'sensibility', characterized by an appropriation of the feminist discourse of women's sexual liberation, so that women are positioned as fully sevually empowered and 'free'. Gi1l has cuggested that the feminist discourse of women as victims of the male gaze has now radically shifted to discourse where women are said to have found freedom through their sexual liberation. Through an analysis of contemporary western (but globalized) advertising media, Gill questions, however, why girls/women's sexual freedom appears to be tied to the performance of particular sexual scripts around pleasing men, and how the female body remains bound through very specific ideals of visual bodily perfection (to be met typically through consumerism and making over the self as part of the body project, see also Ringrose and Walkerdine 2008). Gill says this is a new form of 'compulsory sexual agency' that is now a 'required feature of contemporary postfeminist, neo-liberal [feminine] subjectivity' (2008: 40). The postfeminist sensibility is therefore characterized by the normalization of a form of female sexuality where women are positioned as sexually in control, knowledgeable, practiced and always 'up for it'. According to Gill, the performance of confident sexual agency is not simply 'freeing' an assumption that ties into neo-liberal discourses of agency and choice, but actually functions as a new 'disciplinary technology' of 'sexy' or sexual subjectification (2008: 53).

Scholars have also explored how new technologies of feminine sexiness or practices of feminine hyper-sexualization are part of larger shifts in the 'mainstreaming of sex' or the 'sexualization' of culture and society (Attwood 2009). Sexualization is a problematic, ambiguous notion that has incited popular moral panics over premature child sexualization, for instance, and needs to be treated with care (Gill 2011; Renold and Ringrose, in press). However, like Gill, we do think 'sexualization' (in scare quotes) is useful for signalling the changing nature of sexual representations, particularly the normalization of sexually explicit content in everyday contexts, often related to the normalization of pornography. In the neo-liberal context of celebrating individual freedoms, and a context of wider access via the Internet, pornography has become increasingly deregulated by nation states (Sears 2011). With this deregulation, images and tropes from the media sphere of pornography are mainstreamed and normalized in the everyday cultural realm, a process that has been called pornification (Attwood 2006; Paasonen, Nikunen and Saarenmaa 2007). We draw explicitly on the notion of pornification to think about how the young people draw on 'porno-discourses' to shape their sexual identities.

We find these analyses of postfeminist, sexualized, pornified media contexts, where new compulsory discourses of female sexual agency proliferate, an important place to start thinking about what possible risks and opportunities are facing girls as they construct gendered and sexual digital identities. As suggested young people are not simply rational actors who can/should learn risk aversion; we need to attend to the psychosocial complexity of how sexualized pleasures and dangers unfold online. Post-structural and psychosocial feminist theory and research (Butler 1990; Walkerdine, Lucey and Melody 2001) helps us to explore how young people are multiply positioned and construct sexual/gender identities on their SNSs in psychically complex ways (Thomas 2004). As Gill has suggested we must take great care in theorizing female sexual agency so we do not end up reifying girls and women as either 'docile 
subjects' or the 'autonomously freely choosing persons of neo-liberal humanism' (2008: 40). There is a need to attend to the regulatory gendered and sexist discourses at play in the local data under exploration. Yet, in the context of both online and at school engagements young people are not just viewers of popular culture but are actively constructing an online profile (boyd 2008) and they also have to negotiate/perform some form of sexual identity at school - so we will elaborate how girls are co-constructing but also contesting complex sexualized discourses both online and offline.

\section{PREVIOUS RESEARCH ON GENDERED IDENTITY ONLINE AND IN SNSS}

Previous research exploring teens gendered and sexual identity construction online has focused on issues of gender differences in uses and styles of online interaction between girls and boys. Girl-focused research is extensive, but some examples include exploring the construction of online femininity (Kelly, Pomerantz and Currie 2006) through web logs (Bortree 2005; Sveningsson Elm 2009), gaming (Willett 2006), aspects of girls' online media constructions likes zines and fan sites (Kearney 2006) and even instant messaging (Stern 2007). There is still, however, a general 'lack of sufficient empirical research' on young people's uses and engagements with SNSs, and even less research specifically exploring the construction of girls and boys online gendered and sexual identities (Livingstone and Brake 2010: 80).

Recent research has explored gender identity on MySpace and Facebook but mostly among young adults and college students (Magnuson and Dundes 2008; Manago, Graham, Greenfield et al. 2008). Manago, Graham, Greenfield et al.'s (2008: 446) research into MySpace use among college students in the United States found that while MySpace offered new routes for self-expression and identity online, male-female differences in self-presentation online parallels and possibly intensifies gender norms offline and there were problems of increased pressure for sexual objectification and intensified social comparison online.

As noted, Sonia Livingstone's work has looked at gender differences in children and young people's engagements in SNSs as well as the issue of young people accessing pornography online (Livingstone and Brake 2010). Livingstone and Helsper (2009: 316) reported 41 per cent of British 12-17 year olds have ended up on a porn site by accident and another 9 per cent have visited such a site on purpose. Of the participants in their quantitative study, 33 per cent had had someone say nasty or harmful things to them online. The authors argue we do not know enough about the qualitative nature of how youngsters engage with risks like pornography, although they suggest there is actually minimal risk from adult sexual predators or sexual grooming online. However, this is only one dimension of sexual risks, focusing on the outside-unknown, and high profile, criminal phenomena like paedophilia. We seek to expand an understanding of gendered and sexual risk into the everyday relations in the young people's immediate, inside-known realm of peer-to-peer relations in their social networks both online and offline. We explore the qualitative nature of how porno-chic discourses, discussed as part of postfeminist media cultures, are shaping the construction of online gendered and sexualized identity for girls in particular. 
1 Bebo is a 'teen-friendly' version of Facebook and was the most popular British teen SNS at the time of the research (Smithers 2008). There was a high usage of Bebo in our data sample.

2 All schools and participants and their online usernames have been anonymized.

3 The research was carried out with Rebekah Willett.
The other issue we explore is that of gendered and sexualized cyberbullying; Livingstone and Brake (2010: 77) explored cyberbullying on SNSs, mentioning the possibility of 'racist attacks', but they do not explore the possibility of sexist or sexual attacks from peers, focusing again on the adult/child binary in relation to paedophiles or sexual grooming. In addition to adult sexual predators, there is also the problem of peer sexulal attacks via digital technologies. Some research suggested girls are more at risk of cyberbullying (Rivers and Noret 2010), although the way this manifests in social networks is still largely unknown (Papadopoulos 2010). The risk of sexual/sexist attacks online is also something we explore in this article, suggesting that the ways sexual attacks manifest in social networks, instant messaging and mobile phones are interconnected and can also influence physical attacks at school.

\section{METHODOLOGY: RESEARCHING 'DIGITIZED’ IDENTITY}

Methodologically drawing a binary between online and offline or virtual and face-to-face experiences has been a weakness in prior research on teens and gendered identity online (Livingstone and Haddon 2009). Much research has focused on online data without exploring its significance in the users' offline life and experiences at school, for instance (e.g. Bortree 2005; Moinian 2006; Sveningsson Elm 2009). The research reported here explicitly explored the dynamics between online identity construction and offline school behaviour and relationships. Interviews with young people were undertaken to augment the researcher's understandings of their online content. In presenting the findings, we have sought to capture the dynamic of how online representations mutually shape and impact offline representation and relationships through our use of the notion of digitized identity. We do not want to assert a binary between digital and analogue, or online and offline, or virtual and face-to-face, rather we want to signal how virtual interaction has dramatically shaped the formation of identity. Digital interactions thereby mediate everyday activity, in this case gendered and sexualized practices among young people, in new ways.

As noted, much of the research on SNSs has been mainly quantitative or survey and questionnaire based (see, e.g., Gangadharbatla 2008; Patchin and Hinduja 2010). This study was a qualitative quasi-ethnographic project with the goal of understanding the meanings of young peoples' use of SNSs through their own narrative views. The data collection included researching students' use of the SNS Bebo ${ }^{1}$ through research in two British schools. For our research, we studied a media studies class in year 10 in Thornbury Secondary, ${ }^{2}$ a high-achieving rural specialist college with low levels of socio-economic disadvantage; and a year 11 media studies class at New Mills Secondary, which was in contrast an estate school in a Southern London borough, in an area of high deprivation. The research team ${ }^{3}$ did observations in larger classes, then six focus groups with 23 young people (eleven boys and twelve girls, aged 14-16) where we asked for permission to view their SNSs. We therefore viewed the sites of known participants as part of an ethical commitment to working with young people to uncover the meanings of digital communication, rather than, for instance, purely online ethnography where researchers may not know the participants offline and may not even obtain informed consent (Hine 2008).

After viewing sites, we then returned for individual interviews (six girls, one boy) with students whose sites raised particular issues around gendered/sexual representation. We also did further online observations (virtual ethnography) of the SNS profiles of many of the participants over a period of a several 
months while carrying out the project. In addition to the sites of participants, we explored some friend networks and romantic interests of participants discussed in interviews, as well as some publicly available Bebo sites of young people in the same age range to understand the dynamic, affective nature of the Bebo SNS as an assemblage. ${ }^{4}$ In this article we focus on the case studies of one girl from each school in relation to their peer group interactions, in order to explore the complex dynamics of performing a young feminine sexual digital identity in relation to localized peer groups and the postfeminist media contexts we have outlined.

\section{PORNO-DISCOURSES AND PERFORMING DIGITAL 'SLUT'}

In our first example we explore how a 14-year-old girl Denise from Thornbury Secondary performs/'does' her sexual digital identity through her Bebo profile and how this informs dynamics at school. Contact with Denise began through a group interview at Thornbury High School with a group of students in year 9 (aged 13-14 years). During the interview Denise told the group it was important not to look too 'slutty' online, or to show pictures of their body or their 'cleavage and nothing else', which meant these girls 'thought too much of themselves'. The researcher was surprised, then to view Denise's Bebo page later that day and find that her Bebo user name was 'slut'. Accompanying this was Denise's user name and tagline, which read 'Slut $<$ De- De- Deniseee $>$ 'А Ч Ч Ч Ч Like Your Mum! And I Suck Dick for $£ 5^{\prime}$. Her profile had the background skin of a nude Marilyn Monroe in bed holding a rose with the quotations: 'its all just make believe' and 'A wise girl kisses but doesn't love, listens but doesn't believe, and leaves before she is left.' The visual representations on Denise's site also seemed to contradict Denise's public denouncing of 'sluttiness' and 'cleavage' shots (cf. boyd 2008). For example, Denise's breasts and cleavage were prominent in her profile picture and additional photos on her site. ${ }^{5}$ We were very curious to follow up these points with Denise in an individual interview.
4 SNSs are 'networked publics' (boyd 2008) or networked 'assemblages' of users (Ringrose 2011). Assemblage means that individual users plug into a friendship network, which is in turn plugged into a wider network. Local and global meanings and identifications flow through and shape the possibilities of identification in a networked assemblage like Bebo (see Ringrose 2011 for a fuller analysis of SNSs as 'affective assemblages').

Therefore, it was important to view some of the sites of significant others of our participants, as well as get a wider sense of trends in Bebo among users of this age group. We were careful not to compromise the anonymity of any of the young people.

5 For instance Denise had put one photo of herself through an application to add flashing stars to her cleavage.

\section{Example 1. Interview with Denise}

1. JR: Yeah. Yeah, OK, so now I have to ask you about this [bring out screen print of Bebo profile]. [Laughs]

2. Denise: Yeah. Oh god. Um, that's [the tagline] a bit like that, right, OK. My friend wrote that on there and I was like, right, I'm going to get her back, and I wrote back, um, I[... . I suck nipples for free. [Laughs]

3. JR: Yeah.

4. Denise: But it was just a joke, so it wasn't on there for long. I've checked, It's not on[... . Hers, you can see on like wherever it's gone, it's not on there anymore.

5. JR: Yeah. I don't want you to feel like we're some kind of teacher or something[...]. Because what's interesting to me is[...] the context of it, and also, like, I'm just[...]like what[...]what do you think your friend was[...]up to when she did that?

6. Denise: Well, it started off[...] [Pause] It started off because[...] [Sighs] I can't remember. It was so long ago, but her[.. . ] I think her 
boyfriend cheated on her or something[... . No, no, no. She cheated on her boyfriend Nick.

[Turns omitted]

29. Denise: And then[... ]and then it was just running, like, where we basically swapped Bebos, and she'd write loads of comments on here, like stuff like, Sheridan blah, blah, blah, blah.

30. JR: Oh you can swap Bebos.

31. Denise: No we swapped passwords.

32. Denise: And like just jokes like that. And then it was that. And then she put it on there and I kept it on there for a little while.

33. JR: Mm

34. Denise: And then so did she and we just[...]then we thought, oh that's old now we'll delete it.

[Turns omitted]

35. Denise: It's probably making us look really bad, but. [Laughs]

36. JR: Did you[...]did you mind that that was on your site? Did it [...] Like how did it make you feel?

37. Denise: Ur, I didn't mind because I know she was only joking.

38. JR: Yeah.

39. Denise: 'Cos I was on the phone to her at the same time.

40. JR: Yeah.

41. Denise: So she was going, like, ha ha, look what I've thrown on your Bebo[...] ]and stuff. And then[...] and then[...] So I was like, no, look at your Bebo. It was just like that, so it just started building up and got worse and worse.

In Example 1 we can see how Denise in her initial response, when the interviewer wants to talk about the Bebo page with the tagline (see above), does a lot of defence work: she uses a lot of words denoting embarrassment such as 'yeah', 'oh god', 'um', 'right', 'ok'; she finishes with a laughter. None of this is perhaps surprising given that the interviewer is an adult woman, and the interviewer tries to assuage Denise's worries by dis-identifying as a teacher and therefore authority figure who might seek to discipline her Bebo performance. Denise goes on to explain that she is not solely responsible for the tagline and it happened in an online session with her friend Sheridan, who went on to write on Denise's site, the accompanying tagline 'I suck nipples for free but you have to ask nicely.' The entire exchange also happened while they were on the phone with each other, indicating the multiple communicative modes at play. Denise explains the whole thing was 'just a joke' (turn 4), saying also that she did not keep the tagline on her page for long, but that Sheridan still had her sexually explicit comment on her Bebo page.

Denise also went on to discuss the genesis of the user name 'slut':

\section{Example 2. Interview with Denise}

1. Denise: We have this little thing, like she's my slut, I'm her whore. Because loads of people used to call us it, so we just thought whatever, we'll just be them then. And like one day we just found a background like it, and we were like, oh, that's quite nice. And people are like, why have you got slut[...]and its 
like, I don't mean it like that. But 'cos I didn't know, like if you read it if you'd be thinking, 'Oh my god!'

2. JR: So you mean that people used to say that you were a slut, what do you mean by that?

3. Denise: Well, 'cos our group, like some people, like older girls that saw us, like with someone would be like, oh you slag or you slut because[...]. just because they didn't know us, but just because they wanted to insult us[...] Cos we used to really care about it, and then we just got a bit like oh I don't care anymore[...] we just got used to it, and then [...] I don't really know what happened but it was just a random thing of where we were just like[...] 'she's my whore and I'm her slut. Whatever. Get over it!'. And then she'd say the same.

4. JR: Okay. And how do you think other girls perceive that in your group? What do they think?

5. Denise: I don't know. I haven't had anybody say anything, like girls being bitchy about it to me.

6. JR: I remember you said, you know, other, older guys contact you and stuff, how do you think that might affect how people see you, like wider than your school community?

7. Denise: I suppose that probably entices them a bit. But[...]but like if they do say anything to me I just literally tell them to fuck off!

8. JR: Yeah?

9. Denise: Because[... I I'll look at their Bebo and if they're like over 17 I'm just like, well you look like a bit of a perv to me, can you leave me alone, or something.

In this exchange there are further contradictions between the claim that the virtual user names 'slut' and 'whore' are joking and friendly references to each other and the finding that taking up these identity markers came out of verbal attacks of 'slut' from 'older girls'. Interestingly, among Swedish working-class girls, Ambjörnsson (2004) sees examples of young girls who are friends calling each other whore. Ambjörnsson interprets this as a way of rebelling against the victim position by reclaiming the demeaning label in question. Eriksson Barajas (2010) shows other examples of how the whore position can be used to refuse a victim position and as a way of gaining power in a discussion. On two occasions, a young girl in upper-secondary school indirectly positioned herself as a whore and her male friend as 'pimp' in a spontaneous role play in a discussion about a film on sex trafficking.

Analysing the use of slut is therefore complex, since it appears there is an aspect of what Butler (1997) would term re-signification of the notions of slut and whore, which Denise and Sheridan take on together, becoming each others' slut and whore, which is quite different, for instance, than being a whore to a male pimp. It signals a resistance to sexual bullying and regulation from other girls and also that the meaning of slut may be changing in popular culture and could signal a cool, sexy identity as part of the porno-chic aesthetic, identified as a key postfeminist discourse. ${ }^{6}$ Findings about teens familiarity with pornography through high viewing rates (Livingstone and Brake 2010) have gendered implications here, since Denise and Sheridan use what we have called porno-discourses to present a particular version of sexy and 'knowing' feminine teen subjectivity online (Bragg and Buckingham 2009: 136). There are
6 See Feona Attwood (2007) for an analysis of the shifting meanings of 'slut' in contemporary media discourses. The international phenomena of 'slut walks' occurring at the time of writing in relation to the sexist comments of a

Toronto police

'women should avoid dressing like sluts in order not to be victimised' (McCartney 2011) also seem to signal a complex resignification of the word slut (Butler 1997). For further empirical data analysis of girls' re-workings of 'slut' see Ringrose $(2008,2010)$. 
various opportunities offered by the online space of fantasy and identity construction. But girls have to navigate what being a slut means - is it derogatory or cool? Is this the form of sexual subjectification that Gill (2008) referred to as a new compulsory technology of performing 'up for it' sexiness? Or is it a means to talk back to the injurious norm? The 'slut' position is negotiated in complex ways over time within their c11turally (mixed working and middle class and white) specific peer group.

The interviewer also tries to discuss with Denise her views on how both the peer group and possible outside viewers may relate to this style of representations. Denise says no girls have been 'bitchy' to her about it and also demonstrates that she perceives no risk from adult male 'pervs'. She did, note, however, that the guy (Sam, 15 Thornbury) she was 'seeing' found it 'weird' to be getting messages from 'slut', 'slut', 'slut'.

As feminist researchers, it is critical for us to locate the porno-chic discourses historically, since they relate back to discourses of prostitution. Each of the taglines has references to selling sex for money or performing sexual services for free. Indeed, performing the 'slut' digital identity was a shifting and risky game that illustrated the abiding power of slut as potentially regulatory label. Because our research employed an ethnographic technique of following participants online, we were able to see that Denise shifted identity significantly when she broke up with Sam. Sam began publicly proclaiming his 'luv' for another girl on his Bebo site. While the pornified 'up the bum' tagline had been removed prior, right after the break up Denise changed her user name too, removing slut to become 'Denise'. A possible interpretation of this is that the officially displayed heterosexual relationship works as a shield for the active knowing feminine sexuality, and sexually explicit Bebo identity, while it is perceived as too risky for a single girl to display a slut position online. At this point the research project was completed and there was no opportunity to re-interview Denise about the meanings of her online sexual identity change. However, there are important questions about how such online sexual identity practices offer opportunities for playing with a sexually powerful subject position (see Eriksson Barajas 2010). It is possible to say in both cases that an all-encompassing discourse of sexual victimization and vulnerability of girls and women is negotiated through the performance of pleasure and knowingness in being a 'slut' or 'whore'. Yet Denise's story illustrated 'slut' is still a difficult, ambiguous and unstable subject position within gendered power hierarchies that may continue to regulate the normative dating practices of young heterosexualized masculinities and femininities (Kehily and Nayak 2008). And the public performance at school also demanded a normative denouncing of slut in the focus groups. We see significant gendered implications of these data around how sexualized antagonisms at school play out and are addressed through different forms of sexual performance online.

Some other interesting phenomena arise in turn 9 when Denise suggests that she has a coping strategy for handling unwelcome addresses from potential paedophiles ('pervs'): she checks their age on their Bebo page and gets rid of them (tells them to 'fuck off') if she judges they are too old. However, she does not consider the fact that they could lie about their age, an assumption about user communities confirmed in other research (see boyd 2008). It is also interesting especially in connection to the following section that participants often seemed to lack cohesive strategies for handling unwelcome online addresses from known peers, a phenomenon that is far more common than approaches from unknown adults. 


\section{SEXUALIZED CYBERBULLYING}

In the second set of data examples, we examine further how online relations extend into and shape offline relations at school, specifically exploring the issue of online sexualized name calling or 'sexualized cyberbullying' (Kofoed and Ringrose, in press). In the previous example we looked at the type of sexual identity construction and exploration made possible for Denise as a form of communicative risk and opportunity afforded by the platform of the SNS Bebo. Livingstone and Brake suggest (2010: 77) the 'wide circle of friends[...] sustained by social networking sites' is part of SNSs' importance in lending 'new opportunities for self-expression, communication and networking'. Indeed they suggest an important consequence of SNSs to teens is 'they afford asynchronous, noncommittal, playful interaction in which the management of "face" and negotiation of flirting, misinterpretation and innuendo is more controllable' (2010: 77). The authors go on to suggest there are 'new risks of privacy invasion, bullying and dangerous contacts' but they do not qualify the experience of risk, with the psychological or social (psychosocial) nature of interactions experienced.

The case study of Lottie allows us to both elaborate on and complicate the gendered and sexualized dynamics of risk, exploring how SNSs, instant messaging, phone and face-to-face contact all flow together in the networked assemblage of peer-to-peer connections. We will explore the construction of normative abusive gendered/sexualized identity categories within this usergenerated content and how identity management can actually also become less 'controllable' than in face-to-face interaction.

During the first group interview at New Mills (with year 11 girls, aged 16 years) it emerged that Lottie and Amy had had an MSN (online instant messaging) 'fight':

Example 3. Group Interview with Lottie and Amy (and three other girls)

1. Lottie: We've literally been in a fight before because things have been [...] said that's like, one of my mates told me on MSN that she called me a fat slag and everything like that so then I [...].waited for her outside before school one day and I said 'Why are you saying this for?' and

2. Amy: She punched me in my back.

3. Lottie: I punched her in the back, she razzed in my face, she tried walking away, I grabbed her, punched her again, everything right, because all these things that people say to [...] wind people up[...] she sits there and cries their eyes out, right and I beg to differ that - I will never, ever do it again and I promise -

4. Amy: Because you love me!

5. Lottie: I love you! But the things that people say they don't realize what, how much trouble it can actually cause.

6. JR: $\mathrm{Mmm}$.

7. Amy: Like people were saying to me that, 'Well, she'd been saying that she don't like me, she hates me, she's never liked me.' and then they were saying to her, I'd been calling her a fat slag, I'd been calling her this. 
8. Lottie: So either way everything's been getting twisted.

9. JR: Through the MSN?

10. Lottie: It actually was through MSN! This is the MSN argument that I was trying to think of! - so it's my mate told me on MSN that she had been saying this and then and I said to her, 'Why are you saying it?', she goes 'I'm not that person's lying.'

11. JR: Mmmm.

12. Lottie: So I said, 'You're saying this.' that was my MSN argument and it turned out to be a punch up between me and her[... ]

It is significant that Lottie is positioned as 'fat slag' through the web of discourses circulating through MSN, which is set in opposition to the possibility of being 'sexy' or desirable. She is called fat in contrast to the skinny ideal. She is also called 'slag', a word with working-class connotations. The combination of 'fat slag' implies being physically gross, disgusting and sexually active, or 'loose' but also somehow desperate. It also emerged in individual interview with Lottie that Amy was said to have said 'You go round with everyone. You try and get with everyone's exes and everything like that.' The online rumour leads to Lottie physically attacking Amy, which also positions Lottie as un-feminine, since questions are typically raised about physically aggressive girls, even in UK working-class culture, where girl-to-girl violence is more normalized (Jackson 2006; Ringrose 2006).

Unfortunately despite being the victim of gendered and sexualized gossip, Lottie is the one that is understood and positioned as a bully by the school response, indicating the institutional inability to uncover the deeper meanings of the incident as indicated by other bullying and cyberbullying research (Ringrose 2008). The gossip circulating through MSN and the violence erupting at school are operating in ways that seem entirely out of Lottie's control, since she has no way of knowing whether Amy really did call her a 'fat slag', and yet the rumour circulates constructing an undesirable gendered and sexualized subject position she must navigate. As she commented, this created a 'very bad atmosphere' and 'a lot of fights'.

The virtual geography or architecture of SNSs (Papacharissi 2009) like Bebo is also important in constructing affective relations (Ringrose 2011). In an individual interview it emerged Louise was no one's 'top friend', a complex categorization since (at the time of the research) Bebo had sixteen 'top friends' boxes that appear on one's profile unless the user modifies the site. Although not all users rate this as important, some do. Many teens in this study also used the category of 'other half' (like Facebook 'in relationship with') by putting their best same-sex friend down (if they are not in a romantic relationship). But none of Lottie's friends had chosen her as 'top friend' or 'other half':

\section{Example 4. Interview with Lottie}

1. JR: You have to choose your top friends?

2. Lottie: Yeah, well, it's like on that one[...] it's weird because they want them to be your first. But then why aren't you their first? You want me to be my first? Why am I your third or second? It's what I don't understand. 
3. JR: So how do you negotiate that?

4. Lottie: You just don't do it back. I just let them go round doing it to everyone else and it's like, why should I do it back? You want me to be my first? Why, why am I your third or second?

5. JR: So you don't, so you don't have one where you're the first and she's the first?

6. Lottie: No[...] It's choosing really because, when you're sitting there choosing you have to think about, of, if I don't choose this person what argument can it cause? [...]will it cause an argument, will it, will it?

SNSs like Bebo create a new technological web of affective social relations and gendered and sexualized subject positions that must be navigated via public display, but this is typically linked for teens to an embodied 'real' audience at school as well. What we might term the 'hegemonic heteronormativity' (Butler 1990) of Bebo is sometimes subverted by the young people, by changing love categories to friendship ones, making for creative opportunities on the site. But with Lottie, this opportunity is actually risky, since the forced display of close friendships creates new possible sources of social problems, exclusions and 'arguments'. The shifting hierarchical pecking order of the peer group is exposed via these functions - if you do not choose or are not chosen as a displayed 'friend', it may lead to an argument. It further emerged that the boy Lottie liked would not declare his 'luv' on his or her Bebo page, and she expressed worry that he might be 'embarrassed of her', which is why he 'wants to keep it private for now'.

In our analysis Lottie is in a vulnerable position; this builds upon the analysis of risk offered by Livingstone and Brake (2010) revealing the qualitative gendered, sexualized, but also classed nature of her social positioning and status. She is navigating a web of anxiety, uncertainty and un-fixity in her peer relations and is at risk of social rejection, seen ultimately in her designation as 'fat slag'. The quickly circulating rumours travelling in the assemblage of gossip through MSN instant messaging, working in connection with the hierarchies on her Bebo page, create new sites of instability and insecurity in the virtual which leak over into the real (Kofoed and Ringrose, in press). In some ways the SNS Bebo seemed to aggravate the vulnerabilities and contradictions in Lottie's social positioning and make her more open to rejection by both friends and romantic interests.

In response to being positioned as a bully by the school, in interview Lottie commented that she did not have an 'anger problem', rejecting this pathologizing terminology to some degree, saying people should 'accept her'. Her Bebo site also offered an opportunity to take back some aspect of control at least in the form of self-representation. She posted a blog where she reflected on the difficult peer dynamic she has had to negotiate at school, suggesting some people are 'pains in the effin asses', and offering her own brand of 'advice' to others. In this very specific instance the Bebo profile does work as Livingstone and Brake (2010: 77) suggest to

Dis-embed communication from its traditional anchoring in the faceto-face situation of physical co-location where conventions of trust, authenticity and reciprocity are well understood, re-embedding it in more flexible, complex and ambiguous networks in which, it seems, children share advice and support with peers. 
This does not, however, lift Lottie out of the everyday risks she runs of being subject to gossip, rumour and sexualized and sexist attack at school. We need much more extensive research to follow the actual meanings and implications of young people's attempts to resist phenomena like peer sexualized bullying via the networking opportunities available on sites like Bebo.

\section{SOME CONCLUDING THOUGHTS}

Research on teen's uses of SNSs can provide an important social laboratory for understanding identity construction (boyd and Ellison 2007); and this article has explored some of the gendered and sexualized dynamics of online engagement. In each of our data examples we saw how sexual identity is negotiated online. Virtual space may operate as a place of sexual freedom and play, providing opportunities for communication that open up gender and sexual identity in new ways, where girls can appropriate and restage the identity of 'slut' for instance. But within these very spaces of opportunity there are also harsh norms of gender identity and sexual regulation. There are risky implications of the postfeminist porno-chic discourses of sexual performance that girls must continuously navigate. 'Slut' may not be easy to sustain as a celebratory or ironic identity position as we saw with Denise when she broke up with Sam. Other sexualized terms like 'fat slag' appear to harshly regulate girls and are experienced as abject and un-liveable subject position at least temporarily. These are the qualitative dimensions of gendered and sexualized risks and opportunities, in the form of uncertainties and anxieties, pleasures and subversions that girls and young women are living out on a daily basis that we have sought to make visible in this article.

Given teens online, mobile networked assemblages often remain tightly bound to their peer-based affective communities in school (see also boyd 2008; Livingstone 2008) there is an educational need to address online or mobile technology identity construction among young people, rather than surveilling and punishing the use of SNSs, or banning mobile phones from use in school, which has tended to be the case up till now (Selwyn 2008). In light of our arguments that we are operating in a postfeminist media context where new versions of pornified hyper-sexy femininity are normative, and our illustration of some of the dynamics of porno-chic performance and sexual cyberbullying, we need to find innovative possibilities for pedagogical engagements around these issues. Possible spaces include lessons in media studies (Bragg and Buckingham 2009) as well as in sex and relationship education guidance and curriculum, to engage with issues of 'sexualization', particularly young people's complex uses of pornography or 'porno-discourses', evident from this and other research data (Albury and Lumby 2010).

To conclude, then, there is a need for further qualitative research that unpacks the complexity of how online social networking is impacting digital sexual identity and shaping peer dynamics, including its relationship to gendered and sexual violence and harassment. We still do not know nearly enough about how the new sexual identity performances of teens inform their sexual relations. And while we focused here on data with girls in relation to postfeminist discourses of sexy femininity, further data and analysis are required to gain insight into how girls and boys are constructing and managing new (and old) dynamics of gendered and sexualized risk and opportunity as they perform their sexual identities in their everyday online and offline,'digitized' lives. 


\section{REFERENCES}

Albury, K. and Lumby, C. (2010), 'Too much? Too young?: The sexualisation of children debate in Australia', Media International Australia, 135- May, pp. 141-52.

Ambjörnsson, F. (2004), I en klass för sig/In Another Class, Stockholm: Ordfront.

Attwood, F. (2006), 'Sexed up: Theorizing the sexualisation of culture', Sexualities, 9: 1, pp. 77-94.

(2007), 'Sluts and riot grrrls: Female identity and sexual agency', Journal of Gender Studies, 16: 3, pp. 231-45.

(2009) Mainstreaming Sex. London, IB Taurus.

Ball, S. J. (2008), The Education Debate: Policy and Politics in the 21st Century, Bristol: Policy Press.

Beck, U. (1992), Risk society: Towards a New Modernity, New Delhi: Sage.

Bortree, D. (2005), 'Presentation of self on the web: An ethnographic study of teenage girls' weblogs', Education, Communication \& Information, 5: 1, pp. 25-39.

boyd, d. m. (2008), 'Why youth social network sites: The role of networked publics in teenage social life', in D. Buckingham (ed.), Youth, Identity, and Digital Media, Cambridge, MA: The MIT Press, pp. 119-42.

boyd, d. m. and Ellison, N. B. (2007), 'Social network sites: Definition, history, and scholarship', Journal of Computer-Mediated Communication, 13: 1, article 11, http://jcmc.indiana.edu/vol13/issue1/boyd.ellison.html, Accessed 15 May 2010.

Bragg, S. and Buckingham, D. (2009), 'Too much too young?: Young people, sexual media and learning', in F. Attwood (ed.), Mainstreaming Sex, London: I. B. Tauris, pp. 129-46.

Butler, J. (1990), Gender Trouble: Feminism and the Subversion of Identity, New York: Routledge.

(1997), Excitable Speech: A Politics of the Performative, London: Routledge.

Byron, T. (2008), Safer Children in a Digital World: The Report of the Byron Review, United Kingdom: Department for Children, Schools and Families, and the Department for Culture, Media and Sport.

Eriksson Barajas, K. (2010), 'The pimp and the happy whore. "Doing gender" in film talk in a school setting', Scandinavian Journal of Educational Research, 54: 6, pp. 581-96.

Gangadharbatla, H. (2008), 'Facebook me: Collective self-esteem, need to belong, and internet self-efficacy as predictors of the igeneration's attitudes toward social networking sites', Journal of Interactive Advertising, 8: 2, pp. 5-15.

Gill, R. (2007), 'Post-feminist media culture: Elements of a sensibility', European Journal of Cultural Studies, 10: 2, pp. 147-66.

(2008), 'Empowerment/sexism: Figuring female sexual agency in contemporary advertising', Feminism \& Psychology, 18: 1, pp. 35-60.

- (2011), 'Sexism reloaded, or its time to get angry again!', Feminist Media Studies, 11: 1, pp. 61-71.

Hine, C. (2008), 'Overview: Virtual ethnography: Modes, varieties, affordances', in N. G. Fielding, R. M. Lee and G. Blank (eds), Handbook of Online Research Methods, London: Sage, pp. 257-270.

Jackson, C. (2006), Lads and Ladettes in School: Gender and a Fear of Failure, Maidenhead, UK: Open University Press.

Kearney, M. C. (2006), Girls Make Media, New York: Routledge. 
Kehily, M. J. and Nayak, A. (2008), 'Global femininities: Con)sumption, culture and the significance of place', Discourse: Studies in the Cultural Politics of Education, 29: 3, pp. 325-42.

Kelly, D. M., Pomerantz, S. and Currie, D. H. (2006), ' "No boundaries"? Girls' interactive, online learning about femininities', Youth and Society, 38: 1, pp. 3-28

Kofoed, J. and Ringrose, J. (in press), 'Travelling and sticky affects: Exploring the meanings of sexualized cyberbullying through a Butlerian-DeleuzianGuattarian lens', Discourse.

Livingstone, S. (2008), 'Taking risky opportunities in youthful content creation: Teenagers' use of social networking sites for intimacy, privacy and self-expression', New Media \& Society, 10: 3, pp. 459-77.

Livingstone, S. and Brake, D. (2010), 'On the rapid rise of social networking sites: New findings and policy implications', Children and Society, 24: 1, pp. 75-83.

Livingstone, S. and Haddon, L. (2009), EU Kids Online: Final Report, LSE, London: EU Kids Online (EC Safer Internet Plus Programme Deliverable D6.5).

Livingstone, S. and Helsper, E. (2009), 'Balancing opportunities and risks in teenagers' use of the internet: The role of online skills and internet selfefficacy', New Media \& Society, 12: 2, pp. 309-29.

Magnuson, M. J. and Dundes, L. (2008), 'Gender differences in "social portraits" reflected in MySpace profiles', CyberPsychology and Behavior, 11: 2, pp. 239-41.

Manago, A. M., Graham, M. B., Greenfield, P. M. et al. (2008), 'Selfpresentation and gender on MySpace', Journal of Applied Developmental Psychology, 29: 6, pp. 446-58.

McCartney, J. (2011), 'Are "slut walks" a backwards step?', The Telegraph, 17 May.

McRobbie, A. (2008), The Aftermath of Feminism: Gender, Culture and Social Change, London: Sage.

Moinian, F. (2006), 'The construction of identity on the internet: Oops! I've left my diary open to the whole world!', Childhood, 13: 1, pp. 49-68.

Paasonen, S., Nikunen, P. and Saarenmaa, L. (2007), Pornification: Sex and Sexuality in Media Culture, Oxford: Berg.

Papacharissi, Z. (2009), 'The virtual geographies of social networks: A comparative analysis of Facebook, Linkedln and ASmallWorld', New Media and Society, 11: 1-2, pp. 199-220.

Papadopoulos, L. (2010), Sexualisation of Young People Review, London: Home Office.

Patchin, J. W. and Hinduja, S. (2010), 'Trends in online social networking adolescent use of MySpace over time', New Media and Society, 12: 2, 197-216.

Renold, E. and Ringrose, J. (in press), 'Schizoid subjectivities?: Re-theorising teen-girls' sexual cultures in an era of "sexualisation" ', Journal of Sociology.

Ringrose, J. (2006), 'A new universal mean girl: Examining the discursive construction and social regulation of a new feminine pathology', Feminism and Psychology, 16: 4, pp. 405-24.

(2007), 'Successful girls?: Complicating post-feminist, neo-liberal discourses of educational achievement and gender equality', Gender and Education, 19: 4, pp. 471-89. 
(2008), "Just be friends": Exposing the limits of educational bully discourses for understanding teen girls' heterosexualized friendships and conflicts', British Journal of Sociology of Education, 29: 5, pp. 509-22.

(2011), 'Beyond discourse? Using Deleuze and Guattari's schizoanalysis to explore affective assemblages, heterosexually striated space, and lines of flight online and at school', Educational Philosophy \& Theory, 43: 6, pp. 598-618.

Ringrose, J. and Renold, E. (2010), 'Normative cruelties and gender deviants: The performative effects of bully discourses for girls and boys in school', British Educational Research Journal, 36: 4, pp. 573-596.

Ringrose, J. and Walkerdine, V. (2008), 'Regulating the abject: The TV makeover as site of neoliberal reinvention toward bourgeois femininity', Feminist Media Studies, 8: 3, pp. 227-46.

Rivers, I. and Noret, N. (2010), "I h8 $\mathrm{u}$ ": Findings from a five-year study of text and email bullying', British Educational Research Joumal, 36: 4, pp. 643-71.

Sears, C. (2011), 'Policing the "grotesque": The regulation of pornography in Canada', Ph.D. thesis, Vancouver: Simon Fraser University.

Selwyn, N. (2008), 'Online social networks-friend or foe? Teachers TV program', http://www.teachers.tv/video/24687. Accessed 15 July 2008.

Smithers, R. (2008), 'Bebo named as best social networking site in survey', The Guardian, 4 January.

Stern, S. T. (2007), Instant Identity. Adolescent Girls and the World of Instant Messaging, New York: Peter Lang Publishing.

Sveningsson Elm, M. (2009), 'Exploring and negotiating femininity', Young, 17: 3, pp. 241-64.

Thomas, A. (2004), 'Digital literacies of the cybergirl', E-learning, 1: 3, pp. $358-82$.

Walkerdine, V., Lucey, H. and Melody, J. (2001), Growing Up Girl: Psychosocial Explorations of Gender and Class, Basingstoke: Macmillan.

Willett, R. (2006), 'Poofy dresses and big guns: A poststructuralist analysis of gendered positioning through talk amongst friends', Discourse: Studies in the Cultural Politics of Education, 27: 4, pp. 441-45.

\section{SUGGESTED CITATION}

Ringrose, J., \& Eriksson Barajas, K. (2011), 'Gendered risks and opportunities? Exploring teen girls' digitized sexual identities in postfeminist media contexts', International Journal of Media \& Cultural Politics 7: 2, pp. 121-138, doi: 10.1386/ macp.7.2.121 1

\section{CONTRIBUTOR DETAILS}

Jessica Ringrose is a senior lecturer at the Institute of Education, University of London. Her current research explores postfeminist discourses of 'compulsory sexualization' and teens' performances of sexual identity online and at school.

Contact: Jessica Ringrose, Institute of Education, University of London, 20 Bedford Way, WC1H 0AL London, United Kingdom.

E-mail: J.Ringrose@ioe.ac.uk 
Katarina Eriksson Barajas is an assistant professor in educational sciences at the Department of Social and Welfare Studies at Linköping University, Sweden. She is interested in comparative literature, child studies, gender studies, media reception and discursive psychology.

Contact: Katarina Eriksson Barajas, ISV, Linköping University, SE-601 74 Norrkoping, Sweđen.

E-mail: katarina.eriksson.barajas@liu.se 
Copyright of International Journal of Media \& Cultural Politics is the property of Intellect Ltd. and its content may not be copied or emailed to multiple sites or posted to a listserv without the copyright holder's express written permission. However, users may print, download, or email articles for individual use. 
